\title{
Inhibition of lectin adherence to tissue culture cells by prebiotic carbohydrates
}

\author{
Maria X. Maldonado ${ }^{1}$, Terry Fangman ${ }^{2}$, Alvaro F. Pinto ${ }^{3}$, John H. Rupnow ${ }^{1}$, Robert W. Hutkins ${ }^{1 *}$ \\ ${ }^{1}$ Department of Food Science and Technology, University of Nebraska, Lincoln, USA \\ ${ }^{2}$ Center for Biotechnology, University of Nebraska, Lincoln, USA \\ ${ }^{3}$ Department of Orthopedic Surgery and Rehabilitation, University of Nebraska Medical Center-Scott Technology Center, Omaha, \\ USA \\ Email: *rhutkins1@unl.edu
}

Received 25 October 2012; revised 29 November 2012; accepted 6 January 2013

\begin{abstract}
Prebiotic carbohydrates, in addition to their ability to influence the colonic microbiota, are also able to inhibit attachment of pathogenic bacteria to epithelial cells. This effect is mediated via their structural similarity to the carbohydrate ligands, located on the mucosal cell surface to which bacterial lectins attach. However, the mechanism for this inhibition is not well understood. The goal of this research was to measure the effect of two prebiotic carbohydrates, galactooligosaccharide and polydextrose, on the binding kinetics of plant lectins, having known ligand specificity, to tissue culture cells. To measure adherence, competetion experiments were conducted with HEp-2 cells exposed to nine fluorescent-labeled lectins and either the cognate ligand or a prebiotic. Fluorescence microscopy and image analysis were used to quantify adherence. Lectins that were able to bind to target cells were significantly inhibited in the presence of the cognate ligands. When prebiotics were added, inhibittion of lectin binding was observed, depending on the structural similarity between the prebiotic and the cognate ligands. In general, PDX did not inhibit lectin attachment, whereas GOS significantly inhibited most lectins. This research suggests that receptor sites located on the surface of epithelial HEp-2 cells are structurally similar to GOS.
\end{abstract}

Keywords: Prebiotics; Lectins; Adherence; Tissue Culture

\section{INTRODUCTION}

For most microbial pathogens, adherence or attachment to the host tissue cell surface is required to initiate infections [1]. Adherence provides the means by which

${ }^{*}$ Corresponding author. pathogens resist environmental shear forces, initiate biofilm formation, and begin to colonize or invade host cells [2]. Initially, physical phenomena, including Van der Waal's forces, Coloumbic forces, and hydrophobic interactions, promote bacterial associations with the cell surface, but such interactions are generally loose and reversible [1,3]. More permanent adherence occurs when lectin-like structures attached to the bacterial cell interact with complementary ligands on the mucosal surface $[1$, 3]. These bacterial lectins or adhesins are specialized appendages that are highly stereospecific and determine the tissue tropism of the pathogen. Three general types of adhesin-receptor interactions of different chemical nature have been recognized: 1) recognition between a protein on the surface of the bacteria and a complementary protein on the mucosal surface; 2) binding between hydrophobins in both bacterial and tissue cell surfaces; and 3) binding of lectins with carbohydrate moieties. The latter is the one of the most common mechanisms by which adherence occurs among bacterial pathogens [4].

Lectins, which are also found in viruses, plants, and animals, are proteins capable of specific recognition and reversible binding to carbohydrate moieties without altering the covalent structure of the ligands. Typically, each lectin molecule contains two or more carbohydrate linking sites, and this di- or polyvalency enhances adherence activity. In addition, many bacterial pathogens have the ability to express different adhesins and at different stages of infection $[1,5]$. Thus, it is the concerted action of the different adhesins that allows infections to occur [2].

Prebiotic carbohydrates are defined as food ingredients that provide beneficial effects for the host by selectively stimulating the growth and/or activity of one or a limited number of bacteria in the colon [6]. In addition to their ability to influence the colonic microbiota, however, some prebiotics are also able to interfere with how pathogenic bacteria attach to the epithelial cells 
that line the intestinal tract. This adherence inhibition property has also been attributed to several naturallyoccurring carbohydrates, including milk oligosaccharides, mannan oligosaccharides, and pectic oligosaccharides [7-12]. It has been proposed that the anti-adherence activity of these carbohydrates is due to their structural similarity to the glycans present on the surface of host cells. Accordingly, these soluble carbohydrates would act as receptor analogs and block lectin-carbohydrate interaction and subsequent bacterial attachment. However, the precise molecular mechanism of adherence inhibition is not well understood, in part, because many of the receptor sites on the target cells have not been identified.

One experimental approach to better understand the mechanism of adherence inhibition by bioactive carbohydrates would be to measure adherence of well-defined plant lectins to tissue culture cells in the presence of the putative anti-adherent carbohydrate. The use of these lectins eliminates many of the variables associated with the use of live bacteria ordinarily used in anti-adherence experiments. Such variables include the presence of multiple adhesins with different carbohydrate specificities, variable expression of bacterial adhesions depending on growth phase and environment, and the presence of interfering metabolites produced by bacteria. In addition, plant lectins are well characterized, their cognate ligands are well-defined, and the binding kinetics have been determined [13]. This provides a novel experimental basis to assess how exogenous, structurally similar ligands interfere with lectin attachment in the presence of the cognate ligands. The goal of this research, therefore, was to measure the effect of two prebiotic carbohydrates, galactooligosaccharide (GOS) and polydextrose (PDX), as well as monomeric carbohydrates, on the binding kinetics of lectins to epithelial tissue culture cells. Importantly, the results provide a mechanistic basis for the role of food-grade prebiotics as anti-adherence agents.

\section{MATERIALS AND METHODS}

\subsection{Monosaccharides and Prebiotics Oligosaccharides}

The Monosaccharides used in the present study included glucose, galactose, N-acetyl galactosamine, N-acetyl glucosamine (Sigma Chemical Co., St. Lous, MO, USA) and mannose (Acros Organics, New Jersey, USA). Polydextrose (PDX) was obtained from Danisco (New Century, Kanas). PDX is a D-glucose polymer with $\beta 1-6$ as the predominant linkage between monomers. Small amounts of sorbitol and citric acid, attached to the polymer by mono and diester bonds, are also present. Two forms of galactooligosaccharide (GOS) were used, F-GOS, from Friesland Campina (FrieslandCampina,
New York, USA) and G-GOS, from GTC Nutrition (GTC Nutrition, Golden, CO). Although the degree of polymerization $(2-6)$ and the types of linkages $(\beta 1-3$, $\beta 1-4$, and $\beta 1-6)$ of the GOS in these products are the same, the oligosaccharide concentrations are different. The G-GOS contains $90 \%$ - 92\% GOS, $8 \%$ - 10\% lactose, and traces of glucose and galactose. The F-GOS contains $57 \%$ GOS, and $23 \%$ lactose, $22 \%$ glucose and $0.8 \%$ galactose (maximum values).

\subsection{Lectins}

Nine fluorescein-labeled lectins were obtained (Vector Laboratories, Inc., CA, USA), including Concanavalin A (Con A), Wheat Germ Agglutinin (WGA), Peanut Agglutinin (PNA), Ricinus communis Agglutinin I (RCA), Erythrina cristagalli Lectin (ECL), Euonymus europaeus Lectin (EEL), Soybean Agglutinin (SBA), Ulex europaeus Agglutinin I (UEA I), and Dolichos biflorus Agglutinin (DBA). Sources and carbohydrate specificity are summarized in Table 1.

\subsection{Tissue Culture Conditions}

Hep-2 cells were obtained from the American Type Culture Collection (Manassas, Virginia). Cells were maintained under tissue culture conditions in minimal essential medium (MEM, HyClone, Thermo Fisher Scientific Inc, Utah, USA) supplemented with $10 \%$ fetal bovine serum (FBS, HyClone). For adherence assays, subconfluent monolayers of Hep-2 cells were harvested with $0.25 \%$ (vol/vol) trypsin-EDTA solution (HyClone) and seeded into 24 well tissue culture plates at approximately $5 \times 10^{4} \mathrm{Hep}-2$ cells per well. Plates were incubated under tissue culture conditions for 30 hours before starting the experiment.

\subsection{Lectin Adherence}

Subconfluent Hep-2 cells were prepared as described above. Lectin solutions were prepared in MEM media without FBS (wMEM) and added $(1 \mathrm{ml})$ into each well at a concentration of $7.0 \mu \mathrm{g} / \mathrm{ml}$. Cells were incubated at room temperature for 1 hour in the dark to preserve fluorescein fluorescence. Preliminary studies revealed that 1 hour incubation time was sufficient to induce binding. Wells were then washed twice with wMEM and three times with phosphate buffered saline (PBS) to remove un-bound lectin. Coverslips were fixed with 10\% formaldehyde for $15 \mathrm{~min}$ and washed with PBS. Coverslips were placed in slides and analyzed microscopically (see below). All experiments were performed in duplicate.

\subsection{Competition Experiments}

The same procedure described for the lectin adherence 
Table 1. Plant lectins used in this study, source, and carbohydrate specificity

\begin{tabular}{|c|c|c|c|}
\hline \multirow{2}{*}{ Lectin } & \multirow{2}{*}{ Plant Species } & \multicolumn{2}{|r|}{ Carbohydrate specificity } \\
\hline & & Monosaccharides & Glycans \\
\hline $\begin{array}{l}\text { Concanavalin A } \\
\quad(\text { Con A) }\end{array}$ & Canavalia ensiformis & Man/Glc & $\begin{array}{l}\text { containing } \alpha \text { linked Man } \\
{ }^{*} \text { GlcNAc } \beta 1-2 \text { Man } \alpha 1-6(\text { GlcNAc } \beta 1-2 \text { Man } \alpha 1-3) \operatorname{Man} \beta 1-4 \text { GlcNAc }\end{array}$ \\
\hline $\begin{array}{l}\text { Wheat Germ Agglutinin } \\
\text { (WGA) }\end{array}$ & $\begin{array}{l}\text { Triticum vulgare } \\
\text { (Gramineae) }\end{array}$ & GlcNAc (low affinity) & $\begin{array}{c}\text { Dimers, Trimers, oligosaccharides and glycoproteins } \\
\text { containing GlcNAc, NeuNAc, }(\beta 1-4 \mathrm{GlcNAc}) 1-2 \text { NeuNAc } \\
{ }^{*} \text { GlcNAc } \beta 1-4 \mathrm{GlcNAc} \beta 1-4 \mathrm{GlcNAc} \beta 1-4 \mathrm{GlcNAc} \beta 1-4 \mathrm{GlcNAc}\end{array}$ \\
\hline Peanut Agglutinin (PNA) & Arachis hypogaea & Gal & $\begin{array}{l}\text { Gal } \beta 1-3 \text { GalNAc, Lactose } \\
{ }^{*} \mathrm{Gal} / \beta 1-3 \mathrm{GalNAc-Ser} / \mathrm{Thr}\end{array}$ \\
\hline $\begin{array}{c}\text { Ricinus communis Agglutinin } \\
\text { I } \\
\text { (RCA) }\end{array}$ & $\begin{array}{l}\text { Ricinus communis } \\
\text { (Euphorbiaceae) }\end{array}$ & Gal & $\begin{array}{l}\text { oligosaccharides ending in Gal and NAcGal } \\
\text { *Gal } \beta 1-4 \mathrm{GlcNAc} \beta 1-2 \mathrm{Man} \alpha 1-6(\mathrm{Gal} / 1-4 \\
\text { GlcNAc } \beta 1-2 \mathrm{Man} \alpha 1-3) \mathrm{Man} \beta 1-4 \mathrm{GlcNAc}\end{array}$ \\
\hline $\begin{array}{l}\text { Erythrina cristagalli Lectin } \\
\text { (ECL) }\end{array}$ & Erythrina cristagalli & Gal & $\begin{array}{c}\mathrm{Gal} \beta 1-4 \mathrm{GlcNAc} \\
* \text { GalNAc } \beta 1-4 \mathrm{GlcNAc}-\mathrm{R}\end{array}$ \\
\hline $\begin{array}{l}\text { Euonymus europaeus Lectin } \\
\text { (EEL) }\end{array}$ & $\begin{array}{l}\text { Euonymus europaeus } \\
\text { (Celastraceae) }\end{array}$ & - & $\begin{array}{c}\mathrm{Gal} \alpha 1-3 \mathrm{Gal} \\
{ }^{*} \mathrm{Gal} \alpha 1-3(\mathrm{Fuc} \alpha 1-2) \mathrm{Gal} \beta 1-3 / 4 \mathrm{GlcNAc}\end{array}$ \\
\hline Soybean Agglutinin (SBA) & Glycine max & GalNAc/Gal & $\begin{array}{l}\text { Oligosaccharides with terminal } \alpha \text { - or } \beta \text {-linked NAcGal/Gal } \\
\text { residues }\end{array}$ \\
\hline $\begin{array}{l}\text { Ulex europaeus Agglutinin I } \\
\text { (UEA 1) }\end{array}$ & Ulex europaeus & $\mathrm{Fu}$ & ${ }^{*}$ Fuc $\alpha 1-6 \mathrm{GlcNAc}$ \\
\hline $\begin{array}{c}\text { Dolichos biflorus Agglutinin } \\
\text { (DBA) }\end{array}$ & Dolichos biflorus & GalNAc & $\begin{array}{c}\alpha \text { linked NAcGal } \\
{ }^{*} \text { GalNAc } \alpha 1-3 \mathrm{GalNAc} \alpha 1-3 \mathrm{Gal} \beta 1-4 \mathrm{Gal} \beta 1-4 \mathrm{Glc}\end{array}$ \\
\hline
\end{tabular}

*Glycans for which the lectins have high specificity; ${ }^{\ddagger}$ Adapted from: [13,17,35-37].

experiments was followed. However, for these competition experiments, lectin-carbohydrate solutions were prepared and immediately added $(1 \mathrm{ml})$ to each well. Cognate ligands were added at concentrations of 1,10 and $100 \mathrm{mg} / \mathrm{ml}$ and for oligosaccharides, concentrations of 25,50 and $100 \mathrm{mg} / \mathrm{ml}$ were used.

\subsection{Fluorescence Microscopy}

Slides were observed under an Olympus FV500 Confocal Laser Scanning Microscope with an Inverted Olympus IX81 microscope and a PlanApo 100× oil objective. The $488 \mathrm{~nm}$ Argon laser was used for the fluorescein stained lectins (Vector Laboratories). Using a pre-determined pattern, images from 10 different areas of each coverslip, in duplicate, were obtained for each sample. Each field contained approximately 50 cells.

\subsection{Image Analysis}

MATLAB software (Version 7.8, 2007, The MathWorks, Inc., Natick, Massachusetts) was used to quantify the amount of green contained in each field. The primary spectral component of green was obtained using the RGB color model. The programmed code separates the green channel from the image, and then adds all of the individual values obtained per pixel. Therefore, the total amount of green present in each field was calculated.

\subsection{Statistical Analysis}

Significant differences between the treatments were determined using one-way ANOVA. Post hoc pair-wise comparisons were done using Tukey's test. Differences in lectins attachment were considered significant when P-values were less than 0.05 . GraphPad Prism 5 (version 5.03, GraphPad Software, Inc, 2010) was used to perform statistical tests. All experiments were performed in duplicate.

\section{RESULTS}

\subsection{Attachment of Lectins to Hep-2 Cells}

Nine lectins were assessed for their ability to attach to 
Hep-2 cells. Only five of the tested lectins, Con A, ECL, PNA, RCA, and WGA, adhered to Hep-2 cells. In contrast, cells treated with DBA, SBA, UEA I and EEL lectins did not display any fluorescence signal when observed microscopically.

\subsection{Cognate Ligands Block Lectins Binding to Tissue Culture Cells}

Four of the lectins that adhered to Hep-2 cells were

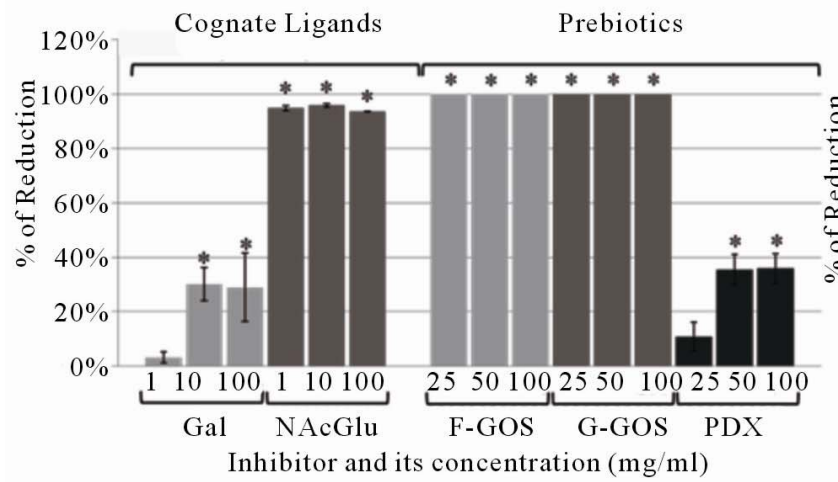

(a)

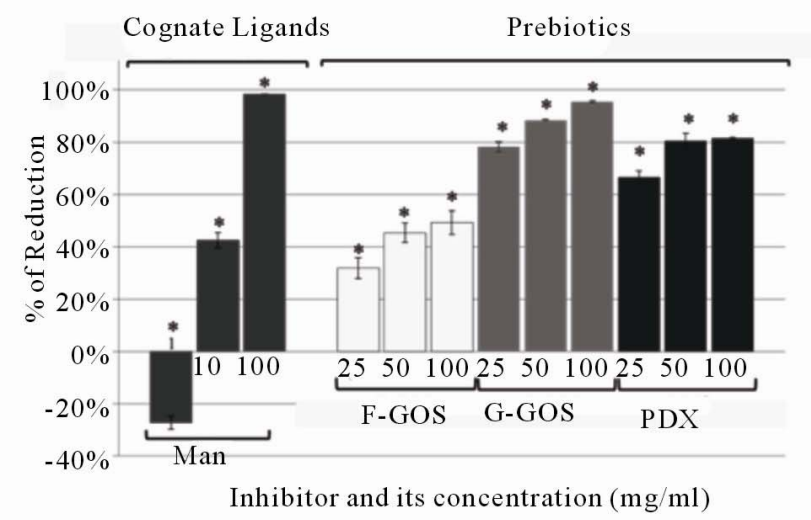

(c)

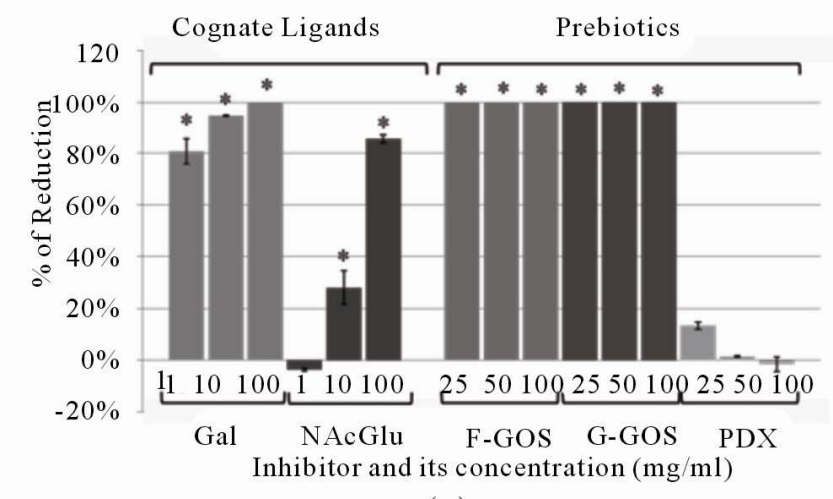

(e ) inhibited by nearly $100 \%$ in the presence of $10 \mathrm{mg} / \mathrm{ml}$ of at least one of their cognate ligands (Figure 1). Con A (Figure 1(c)) was the only lectin for which the presence of the cognate ligand (mannose) did not inhibit binding at the lowest concentration. However, at higher concentrations (i.e., 10 and $100 \mathrm{mg} / \mathrm{ml}$ ), attachment was effectively inhibited by $42 \%$ and $98 \%$, respectively. For those lectins for which two different monosaccharides were used as cognate ligands (Figures 1(a) and (c)), different levels of inhibition were obtained.

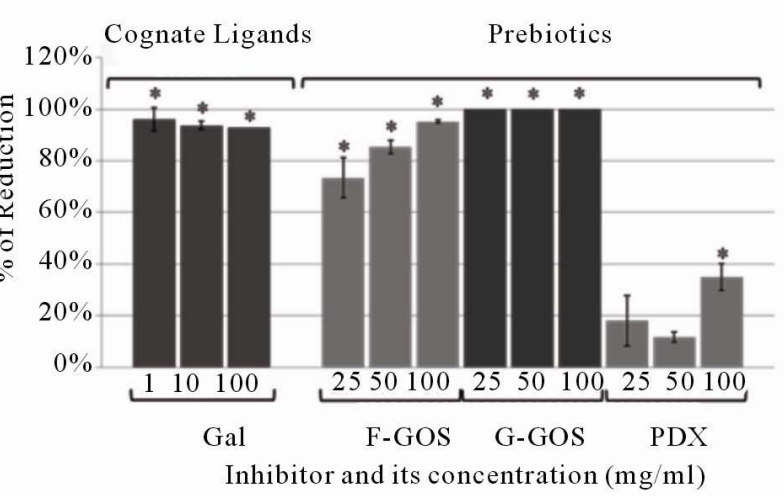

(b)

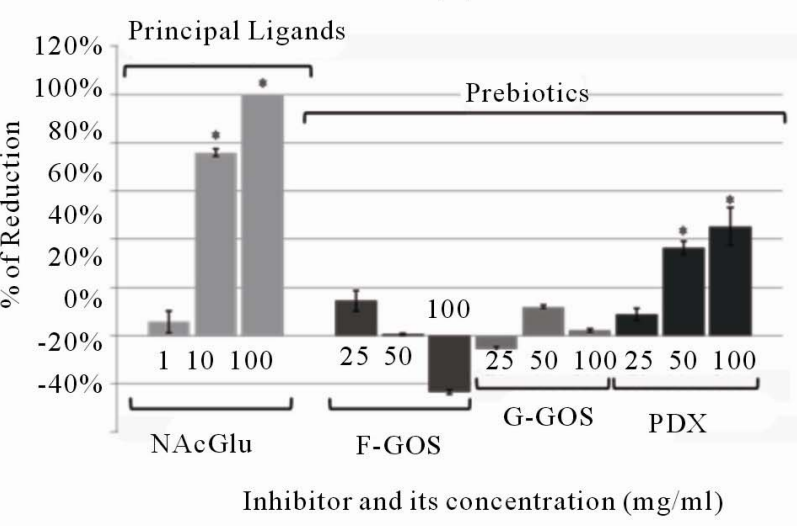

(d)

Figure 1. Lectin attachment in the presence of cognate ligands and prebiotic carbohydrates. Values are reported as the average percentage of reduction $(100 \% \times$ [Control RGB units-Trt RGB units]/Control RGB units) for each of 2 coverslips, based on 10 images per coverslip; (a) Erythrina cristagalli Lectin (ECL); (b) Peanut Agglutinin (PNA); (c) Concanavalin A (Con A); (d) Wheat Germ Agglutinin (WGA); (e) Ricinus communis Agglutinin I (RCA). 


\subsection{Prebiotic Oligosaccharides Inhibit Lectins Attachment to Hep-2}

Prebiotic oligosaccharides also reduced adherence of the lectins to Hep-2 cells (Figures 1 and 2). The concentrations used to test the oligosaccharides were higher than the cognate ligands since the affinity towards these carbohydrates was unknown and less affinity was expected. However, both types of GOS were highly effective at inhibiting attachment. In fact, ECL, PNA and RCA binding was completely inhibited by GOS even when the lowest concentration $(25 \mathrm{mg} / \mathrm{ml})$ was added (Figures 1(a), (b) and (e)). In most cases, $100 \mathrm{mg} / \mathrm{ml}$ of G-GOS was sufficient to inhibit more than $90 \%$ of the lectin attachment.

Although we did not determine the minimum inhibitory concentrations, it is possible that even lower concentrations of these prebiotic carbohydrates might have inhibited adherence of the plant lectins to the Hep-2 cells. In general, G-GOS appeared to block lectin attachment more efficiently than F-GOS and PDX, with the exception of WGA. When Hep-2 cells were exposed to WGA, PDX was the only prebiotic carbohydrate capable of inhibiting attachment; neither G-GOS nor F-GOS had any significant effect. Nevertheless, PDX was not a very efficient inhibitor since $45 \%$ was the maximum level of inhibition reached by PDX for this lectin (Figure 1(d)). The only case in which PDX blocked lectin attachment at rates comparable to that of GOS was in the Con A lectin competition assay. Indeed, higher inhibition of this lectin was obtained in presence of PDX than F-GOS (Figure 1(c)).

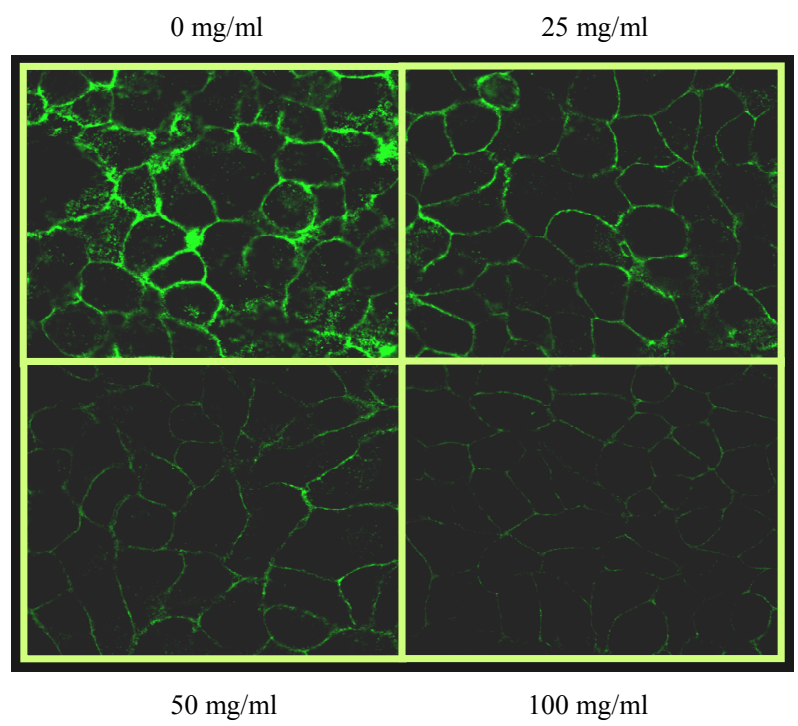

Figure 2. Microscopic images of HEp-2 cells after competition experiments $(100 \times)$. Inhibitory effect of G-GOS on Con A (fluorescein-labeled) attachment the amount of green is directly proportional to the amount of bound lectin and inversely proportional to the percentage of inhibition.

\section{DISCUSSION}

Plant lectins have been shown to be valuable reagents for identifying and characterizing carbohydrate ligands in biological systems [14-16]. In particular, fluorescentlylabeled lectins, in combination with micro arrays and flow cytometry, have been used to analyze cell surface carbohydrates in several tissue cell lines [17,18]. In this current study, plant derived lectins were used to clarify the mechanism by which prebiotic oligosaccharides compete with cognate ligand in the surface of HEp-2 cells. The first step of this approach was to measure lectin attachment directly to HEp-2 cells, which provided a basis for predicting the ligand composition of these cells. Subsequent competition experiments also enabled us to assess how similar these prebiotic carbohydrates were to the HEp-2 ligands.

The observation that several plant-derived lectins, including Con A, ECL, PNA, RCA, and WGA, attached to HEp-2 cells implies that the HEp-2 cell surface contains one or more of the carbohydrate moieties to which these lectins specifically bind. Specifically, these binding sites likely contain glucose, galactose, $\alpha$-linked mannose, $\mathrm{N}$-acetyl glucosamine, dimers or oligosaccharides containing $\mathrm{N}$-acetylglucosamine and/or glycans with the linkages Gal $\beta 1-3 \mathrm{GalNAc}$ or Gal $\beta 1-4 \mathrm{GlcNAc}$. However, to our knowledge, the carbohydrates present in the lectin binding sites located on the HEp-2 cell surface have not been identified.

The carbohydrate specificities of several of the adhesins produced by pathogenic bacteria are now known [5]. For example, P-fimbriated uropathogenic Escherichia coli strains contain an adhesin specific for Gal $\alpha 1-4 \mathrm{Gal}$ [19], whereas other E. coli, as well as Klebsiella pneumoniae and Salmonella, produce adhesins that bind to mannose residues $[1,20-24]$. In contrast, the gram positive organism, Streptococcus pneumonia, binds carbohydrates containing the linkages Gal $\beta 1-3 \mathrm{GalNAc}$ and Gal $\beta 1$ 4 GluNAc $[5,25,26]$. The observation that all of these organisms adhere to HEp-2 cells suggests the presence of a diverse array of carbohydrates receptors to which their adhesins are able to bind [20,26-29]. This is also supported by the plant lectin binding experiments reported here. Indeed, our results suggests that the glycan targets to which these bacterial adhesins bind are likely present in the HEp-2 cells surface, since the plant lectins specific for those targets attached effectively in these experiments.

To assess the ability of prebiotics to act as adhesin inhibitors, competitive binding experiments were performed using the plant derived lectins for which the cognate receptors were already established. As expected, all of the cognate ligands were able to inhibit lectin attachment, confirming that lectins were able to bind to soluble 
carbohydrates, reducing the number of free lectins able to bind the epithelial cells receptors. Prebiotics were also capable of binding to the lectins and reducing adherence, consistent with their monomer composition and the known lectin targets. In general, the greater the similarity between the prebiotic and the cognate ligands, the greater was the inhibition observed. For example, GOS inhibited attachment of ECL, PNA and RCA, lectins that are selective for galactose-containing ligands.

Although both GOS products had similar adherence inhibition activities, G-GOS was more inhibitory, presumably due to the higher concentration of oligosaccharides present in that formulation (91\%) compared to FGOS $(57 \%)$. In contrast, PDX had little $(<40 \%)$ or no effect on adherence of these lectins. Inhibition due to F-GOS is mostly attributed to the GOS molecules. However, for ConA free glucose molecules present in this material could have partially contributed to the inhibitory effect. Although mannose is the primary ligand for Con A, this lectin also has affinity for glucose, but only about a fifth of that for mannose [30].

The cognate ligands monosaccharides for Con A are glucose and mannose; therefore, both PDX and GOS were expected to inhibit Con A attachment. Although PDX consists mostly of glucose monomers and GOS contains only one glucose monomer per molecule, the latter was observed to have higher adherence inhibition. This result could be due to differences in the linkages and monomer distribution of each of the oligosaccharides. It is also possible that the branched structure of PDX causes steric hindrance, and therefore, diminishes it binding affinity. In contrast, the linear structure of GOS molecules could reach the active site of the lectin more easily.

Interestingly, PDX, but not GOS, inhibited WGA binding, although this lectin is not specific for either glucose or galactose residues. The cognate ligand of WGA is the negatively charged $\mathrm{N}$-acetyl glucosamine. Therefore, the inhibition observed could be due to the presence of negative charges contained within the PDX molecule that interfere with lectin attachment to the target cells.

Collectively, these data showing that GOS effectively inhibited attachment of lectins to HEp-2 cells are consistent with the observation that GOS also inhibits adherence of pathogens and their toxins to HEp-2 and other cell lines. Examples include the inhibition of Salmonella, enteropathogenic E. coli, Cronobacter sakazakii and Vibrio cholerae toxin adherence to epithelial cells and cell surface receptors [31-34]. In contrast, PDX did not inhibit lectin attachment, suggesting that it is not effective as an adherence inhibition agent. Moreover, the results confirm the utility of HEp-2 as a suitable cell line to assess the adherence inhibition properties of prebiotic carbohydrates, and validate the proposed mechanism of action of prebiotics as bacterial binding inhibitors.

\section{REFERENCES}

[1] Ofek, I., Hasty, D.J. and Doyle, R.J. (2003) Bacterial adhesion to animal cells and tissues. American Society for Microbiology, Washington DC.

[2] Klemm, P., Vejborg, R.M. and Hancock. V. (2010) Prevention of bacterial adhesion. Applied Microbiology and Biotechnology, 88, 451-459.

doi:10.1007/s00253-010-2805-y

[3] Busscher, H.J. and Weerkamp, A.H. (1987) Specific and non-specific interactions in bacterial adhesion to solid substrata. FEMS Microbiology Letters, 46, 165-173. doi:10.1111/j.1574-6968.1987.tb02457.x

[4] Pieters, R.J. (2011) Carbohydrate mediated bacterial adhesion. In: Linke, D. and Goldman, A., Eds., Bacterial Adhesion. Chemestry, Biology and Physics, Springer, New York, 227-240.

[5] Ohlsen, K., Oelschlaeger, T.A., Hacker, J. and Khan. A.S. (2009) Carbohydrate receptors of bacterial adhesions: Implications and reflections. Topics in Current Chemistry, 288, 17-65. doi: $10.1007 / 128 \_2008 \quad 10$

[6] Gibson, G. and Roberfroid, M.B. (1995) Dietary modulation of the human colonic microbiota: Introducing the concept of prebiotics. Journal of Nutrition, 125, 14011412.

[7] Ganan, M., Collins, M., Rastall, R., Hotchkiss, A.T., Chau, H.K., Carrascosa, A.V. and Martinez-Rodriguez, A.J. (2010) Inhibition by pectic oligosaccharides of the invasion of undifferentiated and differentiated Caco-2 cells by Campylobacter jejuni. International Journal of Food Microbiology, 137, 181-185. doi:10.1016/j.ijfoodmicro.2009.12.007

[8] Ganan, M., Carrascosa, A.V., Pascual-Teresa, S. and Martinez-Rodriguez, A.J. (2009) Inhibition by yeast-derived mannoproteins of adherence to and invasion of caco-2 cells by Campylobacter jejuni. Journal of Food Protection, 72, 55-59.

[9] Spring, P., Wenk, C., Dawson, K. and Newman, K. (2000) The effects of dietary mannaoligosaccharides on cecal parameters and the concentrations of enteric bacteria in the ceca of salmonella-challenged broiler chicks. Poultry Science, 79, 205-211.

[10] Cravioto, A., Tello, A., Villafán, H., Ruiz, J., del Vedovo, S. and Neeser, J.R. (1991) Inhibition of localized adhesion of enteropathogenic Escherichia coli to HEp-2 cells by immunoglobulin and oligosaccharide fractions of human colostrum and breast milk. The Journal of Infectious Diseases, 163, 1247-1255. doi:10.1093/infdis/163.6.1247

[11] Martin-Sosa, S., Martin, M.J. and Hueso, P. (2002) The sialylated fraction of milk oligosaccharides is partially responsible for binding to enterotoxigenic and uropathogenic Escherichia coli human strains. Journal of Nutrition, 132, 3067-3072.

[12] Newburg, D.S., Ruiz-Palacios, G.M. and Morrow, A.L. (2005) Human milk glycans protect infants against en- 
teric pathogens. Annual Review of Nutrition, 25, 37-58. doi:10.1146/annurev.nutr.25.050304.092553

[13] Rüdiger, H. and Gabius, H.J. (2001) Plant lectins: Occurrence, biochemistry, functions and applications. Glycoconjugate Journal, 18, 589-613. doi:10.1023/A:1020687518999

[14] Pusztai, A., Bardocz, S. and Ewen, S.W. (2008) Uses of plant lectins in bioscience and biomedicine. Frontiers in Bioscience, 13, 1130-1140. doi:10.2741/2750

[15] Zeng, X. and Shen, Z. (2008) Microorganism detection and analysis using carbohydrate and lectin recognition. US Patent No. 2008/0193965A1, 1-24.

[16] Koliwer-Brandl, H., Siegert, N., Umnus, K., Kelm, A., Tolkach, A., Kulozik, U., Kuballa, J., Cartellieri, S. and Kelm, S. (2011) Lectin inhibition assays for the analysis of bioactive milk sialoglycoconjugates. International Dairy Journal, 21, 413-420. doi:10.1016/j.idairyj.2011.01.005

[17] Chen, S., Zheng, T., Shortreed, M.R., Alexander, C. and Smith, L.M. (2007) Analysis of cell surface carbohydrate expression patterns in normal and tumorigenic human breast cell lines using lectin arrays. Analytical Chemistry, 79, 5698-5702. doi:10.1021/ac070423k

[18] Alam, S.M., Whitford, P., Cushley, W., George, W.D. and Campbell, M. (1990) Flow cytometric analysis of cell surface carbohydrates in metastatic human breast cancer. British Journal of Cancer, 62, 238-242. doi:10.1038/bjc.1990.267

[19] Mobley, H.L., Jarvis, K.G., Elwood, J.P., Whittle, D.I., Lockatell, C.V., Russell, R.G., Johnson, D.E., Donnenberg, M.S. and Warren, J.W. (1993) Isogenic P-fimbrial deletion mutants of pyelonephritogenic Escherichia coli: The role of $\alpha \mathrm{Gal}(1-4) \beta \mathrm{Gal}$ binding in virulence of a wild-type strain. Molecular Microbiology, 10, 143-155. doi:10.1111/j.1365-2958.1993.tb00911.x

[20] Boudeau, Ã., Barnich, N. and Darfeuille-Michaud, A. (2001) Type 1 pili-mediated adherence of Escherichia coli strain LF82 isolated from Crohn's disease is involved in bacterial invasion of intestinal epithelial cells. Molecular Microbiology, 39, 1272-1284. doi:10.1111/j.1365-2958.2001.02315.x

[21] Strömberg, N., Marklund, B.-I., Lund, B., Hamers, A., Gaastra, W. and Anders, K.A. (2010) Host-specificity of uropathogenic Escherichia coli depends on differences in binding specificity to Gala 1-4Gal-containing isoreceptors. The EMBO Journal, 9, 2001-2010.

[22] Fader, R.C. and Davis, C.P. (1980) Effect of piliation on Klebsiella pneumoniae infection in rat bladders. Infection and Immunity, 30, 554-561.

[23] Kisiela, D., Laskowska, A., Sapeta, A., Kuczkowski, M., Wieliczko, A. and Ugorski, M. (2006) Functional characterization of the FimH adhesin from Salmonella enterica serovar enteritidis. Microbiology, 152, 1337-1346. doi:10.1099/mic.0.28588-0

[24] Firon, N., Ofek, I. and Sharon, N. (1983) Carbohydrate specificity of the surface lectins of Escherichia coli, Klebsiella pneumoniae, and Salmonella typhimurium. Carbohydrate Research, 120, 235-249. doi:10.1016/0008-6215(83)88019-7
[25] Idänpään-Heikkilä, I., Simon, P.M., Zopf, D., Vullo, T., Cahill, P., Sokol, K. and Tuomanen, E. (1997) Oligosaccharides interfere with the establishment and progression of experimental pneumococcal pneumonia. International Journal of Infectious Diseases, 176, 704-712. doi:10.1086/514094

[26] Pracht, D., Elm, C., Gerber, J., Bergmann, S., Rohde, M., Seiler, M., Kim, K.S., Jenkinson, H.F., Nau, R. and Hammerschmidt, S. (2005) PavA of Streptococcus pneumoniae modulates adherence, invasion, and meningeal inflammation. Infection and Immunity, 73, 2680-2689. doi:10.1128/IAI.73.5.2680-2689.2005

[27] Bidhendi, S.M., Sattari, M., Pourbakhsh, S.A., Mobarez, A., Vandyousefi, J., Khaki, P., Heidari, M.H. and Kazemnejad, A. (2007) Blocking adherence of uropathogenic Escherichia coli isolate to HEP-2 cells and bladder of mice in the presence of antibody against p-fimbriae. Biologicals, 35, 99-105.

doi:10.1016/j.biologicals.2006.03.012

[28] Nguyen Thi, P.L., Yassibanda, S., Aidara, A., Le Bouguénec, C. and Germani, Y. (2003) Enteropathogenic Klebsiella pneumoniae HIV-infected adults, Africa. Emerging Infectious Diseases Journal, 9, 135-137. doi:10.3201/eid0901.020138

[29] Boddicker, J.D., Ledeboer, N.A., Jagnow, J., Jones, B.D. and Clegg, S. (2002) Differential binding to and biofilm formation on, HEp-2 cells by Salmonella enterica Serovar typhimurium is dependent upon allelic variation in the fimH gene of the fim gene cluster. Molecular Microbiology, 45, 1255-1265. doi:10.1046/j.1365-2958.2002.03121.x

[30] Searle, L.E.J., Best, A., Nunez, A., Salguero, F.J., Johnson, L., Weyer, U., Dugdale, A.H., Cooley, W.A., Carter, B., Jones, G., Tzortzis, G., Woodward, M.J. and La Ragione, R.M. (2009) A mixture containing galactooligosaccharide, produced by the enzymic activity of Bifidobacterium bifidum, reduces Salmonella enterica Serovar typhimurium infection in mice. Journal of Medical Microbiologyy, 58, 37-48. doi:10.1099/jmm.0.004390-0

[31] Shoaf, K., Mulvey, G.L., Armstrong, G.D. and Hutkins, R.W. (2006) Prebiotic galactooligosaccharides reduce adherence of enteropathogenic Escherichia coli to tissue culture cells. Infection and Immunity, 74, 6920-6928. doi:10.1128/IAI.01030-06

[32] Sinclair, H.R., de Slegte, J., Gibson, G.R. and Rastall, R.A. (2009) Galactooligosaccharides (GOS) inhibit $V i$ brio cholerae toxin binding to its GM1 receptor. Journal of Agricultural and Food Chemistry, 57, 3113-3119. doi:10.1021/jf8034786

[33] Quintero, M., Maldonado, M., Perez-Munoz, M., Jimenez, R., Fangman, T., Rupnow, J., Wittke, A., Russell, M. and Hutkins, R. (2011) Adherence inhibition of Cronobacter sakazakii to intestinal epithelial cells by prebiotic oligosaccharides. Current Microbiology, 62, 1448-1454. doi:10.1007/s00284-011-9882-8

[34] Poretz R.D. and Goldstein I.J. (1970) An examination of the topography of the saccharide binding sites of concanavalin $\mathrm{A}$ and of the forces involved in complexation. Biochemistry, 9, 2890-2896. doi:10.1021/bi00816a021

[35] Iskratsch, T., Braun, A., Paschinger, K. and Wilson, I.B.H. 
(2009) Specificity analysis of lectins and antibodies using remodeled glycoproteins. Analytical Biochemistry, 386, 133-146. doi:10.1016/j.ab.2008.12.005

[36] Munson, L., Kao, J.J. and Schlafer, D.H. (1989) Characterization of glycoconjugates in the bovine endometrium and chorion by lectin histochemistry. Journal of Repro- duction and Fertility, 87, 509-517. doi:10.1530/jrf.0.0870509

[37] Lis, H. and Sharon, N. (1986) Lectins as molecules and as tools. Annual Review of Biochemistry, 55, 35-67. doi:10.1146/annurev.bi.55.070186.000343 